\title{
A comunicação, o comum e a alteridade: para uma epistemologia da experiência estética ${ }^{1}$ \\ Communication, the common and the alterity: for an epistemology of the aesthetic experience
}

\author{
Angela Cristina Salgueiro Marques | Universidade Federal de Minas Gerais \\ Doutora em Comunicação Social pela UFMG. Professora do Programa \\ de Pós-Graduação da Universidade Federal de Minas Gerais (UFMG). \\ E-mail: angelasalgueiro@gmail.com \\ Luis Mauro Sá Martino | Faculdade Cásper Líbero (SP) \\ Doutor em Ciências Sociais pela Pontifícia Universidade Católica de São Paulo. \\ Professor do Programa de Pós-Graduação em Comunicação da Faculdade Cásper Líbero. \\ E-mail: Imsamartino@gmail.com
}

\section{Resumo}

Embora a noção de "experiência estética" venha sendo explorada nos estudos de comunicação, a dimensão estética do conceito em si parece ter sido de alguma maneira preterida, historicamente, em favor de estudos que privilegiam os "meios", no sentido técnico, à "comunicação", em sentido relacional. Este artigo, pautado em pesquisa bibliográfica, procura ressaltar o estético como uma categoria indissociável do conceito de "comunicação" a partir de três pontos: (a) situando a estética da comunicação no conjunto de pesquisas da área; (b) sublinhando a necessidade de pensar o estético como parte do conceito de comunicação; (c) indicando como a narração da experiência pode ser vivenciada como ato comunicativo, político e estético.

Palavras-Chave: Comunicação; Estética; Experiência.

\begin{abstract}
Although the notion of 'aesthetic experience' has been often explored in communication studies, the aesthetical dimension of communication itself has been a road less traveled in current research. This paper outlines some aspects of the aesthetic experience as a component indelibly connected to the very notion of a communication epistemology. The paper, grounded on bibliographical research, argues that: (a) research has put aside the aesthetical dimension of the communication experience by privileging 'media' instead of 'communication'; (b) aesthetics is a fundamental category to understand what is communication; (c) the notion of 'narrated experience' might be seen as an aesthetical, political and communicative act.
\end{abstract}

Keywords: Communication; Aesthetics; Experience. 
Pesquisas recentes desenvolvidas na área de Comunicação têm apostado em uma perspectiva que busca aproximar a arte da vida cotidiana de maneira a revelar como a experiência pode ser pensada a partir das estratégias de ação dos sujeitos diante do mundo e do outro (GUIMARÁES; FRANÇA, 2006; GUIMARÁES; LEAL, 2007). Acreditamos que uma aproximação entre a estética e a Comunicação deve privilegiar o aspecto relacional que caracteriza a ambas.

A significância atribuída a uma obra de arte ou a um produto comunicacional deriva da possibilidade que oferecem à fruição individual, mas também à troca e ao compartilhamento das impressóes vividas pelos sujeitos. Nesse sentido, uma estética da comunicação não se reduz aos meios ou a seus produtos, mas procura evidenciar como os enunciados mediados estabelecem um diálogo com a sociedade, articulando discursos e colocando experiências em contato (LOPES, 2006).

Este texto procura delinear algumas das dimensôes estéticas do conceito de comunicação a partir de sua intersecção com a noção de "experiência", entendida como fundamental para se pensar o conceito. A partir de pesquisa bibliográfica, argumenta-se que pensar a comunicação em perspectiva estética oferece uma trilha frutífera para a compreensão dos fenômenos comunicacionais e, em termos metacríticos, do próprio conceito de comunicação.

Primeiramente, o lugar da discussão estética nos estudos de comunicação será brevemente recuperado, de maneira a indicar como a questão se situa nas reflexões da área. Em seguida, a dimensão estética da experiência será discutida, propondo-se, no final, pensar a comunicação como uma relação fundamentalmente estética de experiência da alteridade.

\section{A dimensão estética no debate epistemológico da área}

A busca por pensar a Comunicação a partir de uma definição estética pode ser compreendida contra o pano de fundo de algumas questôes epistemológicas que vêm se estabelecendo na área. Alguns dos debates recentes, realizados tanto no Brasil quanto no exterior, vêm apontando para a necessidade de repensar o que pode ser definido como Comunicação e, nesse aspecto, o conceito estético emerge como uma proposta em diálogo crítico com outras perspectivas. Vale indicar, sem pretensão à exaustividade, alguns pontos desse tensionamento.

A dimensão estética do conceito de comunicação, em termos iniciais, está ligada ao aparecimento, nos estudos da área, de uma perspectiva que procurou ultrapassar uma determinada concepção de "comunicação" que privilegiava o estudo das "mídias" em detrimento de uma perspectiva que levasse em consideração não exatamente o fenômeno dos meios de comunicação, pensados em sua dimensão técnica ou mesmo sociológica, mas procurasse deslocar o foco para os processos comunicacionais em si, colocados em primeiros plano diante de um modo de olhar que realça o sóciotécnico - vejam-se, por exemplo, os mapeamentos críticos feitos por França (2001, 2013), L. C. Martino (2001, 2002) ou L. M. S. Martino (2008, 2011a, 2011b). 
Sublinhar a dimensão estética do conceito de comunicação demanda, entâo, que se volte ao próprio conceito, procurando sempre ter em mente as trilhas que o privilegiam em relação aos "meios de comunicação". A concepção de "comunicação" que queremos destacar aqui, apesar de parecer ter ficado em segundo plano diante dos estudos centrados nos meios, contempla uma gama maior de situaçôes que não a relação entre "mídia e sociedade", mas que permite compreender a relação entre indivíduos, grupos e comunidades de um ponto de vista que se entenda como "comunicacional" e, para isso mesmo, aponte seus próprios limites e definiçóes de alcance.

Trata-se de pensar a "comunicação" como o domínio do estabelecimento de um tipo específico de relação social que, ao menos em termos epistemológicos, não se confunde ou deveria confundir com o tipo de interação estudado, por exemplo, pela Psicologia ou pelas Ciências Sociais (BENNET, 2003). A especificidade de uma relação comunicacional não se identifica diretamente com as possibilidades abertas, e ao mesmo tempo delimitadas, por outros tipos de relação social. Uma das principais buscas epistemológicas da área, ao menos a partir dos anos 2000, refere-se à possibilidade de encontrar essa delimitação específica sem, evidentemente, deixar de lado os tensionamentos e transversalidades com outras áreas do saber, e mesmo com outras perspectivas dentro da Área de Comunicação (MAIGRET, 2000).

A menção a uma diferença entre "comunicação" e "meios de comunicação" não procura estabelecer mais uma dicotomia dentro do campo das ciências sociais, muito menos traçar linhas estanques entre ambos. É necessário, no entanto, observar que, dentro de uma História das Ciências, enquanto a noção de "comunicação" parece apontar para estudos fundamentalmente amplos, a pesquisa em "meios de comunicação" vem definindo, historicamente, o surgimento e a consolidação de uma área do saber específica. É o estudo dos meios, não da "comunicação", em si, que delimitou historicamente as fronteiras da Área de Comunicação, ao menos, mas não exclusivamente, no caso brasileiro.

O elemento propriamente comunicacional, quando existe, reduz-se, segundo Braga (2010, 2011), a um "epifenômeno" de outros fatores sociais que se tornam, eles sim, os grandes objetos de estudo aos quais se dedica tempo e energia na construção de pesquisas. Nessa situação, que obviamente se constitui a partir de um recorte do observável e não se pretende totalizante, o estudo dos "meios de comunicação" parece deixar de lado a "comunicação", em termos específicos. Não se comunga aqui com a perspectiva de que estudos de "mídia" não sejam "comunicação", ou que uma "sociologia dos meios" não pertença, ou não possa pertencer, à Área de Comunicação (MARCONDES FILHO, 2007); a própria porosidade da Área, como indicada por vários autores, torna difícil esse tipo de separação. Assim, observa-se a intersecção de fenômenos sociais e meios de comunicação, sem necessariamente que a estes últimos seja reservado um papel como vetor de determinação do social. (ALBUQUERQUE, 2002; BARROS, 2008; BRAGA, 2010; MARCONDES FILHO, 2012; FELINTO, 2011; PIMENTA, 2011; FERREIRA, 2012). 
O questionamento dessa perspectiva, dentro da área, pode ser observado ao menos de maneira parcial como um desdobramento da insuficiência de uma sociologia dos meios de comunicação para dar conta de processos comunicacionais que se estendem em redes de significados, apropriaçôes e reapropriaçóes para além das mensagens midiáticas. Se o modelo centrado nos meios pode ser produtivo quando se fala em termos de "produção" e "audiência" de uma mensagem e, portanto, em uma perspectiva com variáveis de controle relativamente definíveis, por outro lado os próprios estudos que ultrapassavam o espaço dos limites imediatos para uma busca mais detalhada das relaçóes entre mídia e sociedade, como no caso dos Estudos de Recepção ou das Análises do Discurso, mostravam que o próprio entendimento dos meios demandava uma definiçáo mais aproximada do que era "comunicação". Dessa maneira, em uma paráfrase do título erigido em paradigma da obra de Martín-Barbero (1997), trata-se de uma passagem "dos meios à comunicação" como perspectiva de compreensão do que se entende por "comunicação" em si mesma.

A comunicação expressa um incontido desejo de estar com o outro, de aceitar o desafio que o outro nos lança por meio de sua singularidade, de sua diferença. O encontro com o outro, em sua dimensão comunicacional, estética e política, se expressa sempre de forma agonística, na qual um indivíduo incita e interpela o outro por meio da dúvida, do estranhamento, do convite à interlocução. É no cotidiano que a comunicação com o outro se fortalece, se redimensiona e redimensiona os sujeitos e o meio no qual se inserem. Comunicar exige o estabelecimento de um sistema normativo e valorativo comum, um conjunto de afetos e açóes compartilhadas dentro da relação que se estabelece entre os indivíduos. Nesse processo, o reconhecimento do mundo do outro deve envolver, além de dimensóes estéticas, éticas e políticas, uma comunicação ligada às práticas compartilhadas dos indivíduos

\section{A dimensão estética do conceito de comunicação}

Em termos comunicacionais, os fenômenos estéticos parecem ter uma dimensão fundamental no estabelecimento da relação com o outro. Ao levar em consideração um determinado conceito relacional de comunicação, que se opóe a uma perspectiva técnico ou mídiacêntrica, o encontro com o outro passa a ocupar um lugar central na proposição, e mesmo na verificação, das condiçôes epistemológicas do estabelecimento do ato comunicacional. O encontro estético com o outro é uma ação própria da Comunicação, entendida nessa perspectiva; é no momento do compartilhamento do sensível erigido em terreno comum que pode se dar, efetivamente, a comunicação.

No entanto, nota-se imediatamente que essa perspectiva pode ser problematizada em termos de uma dupla abertura, não apenas em relaçáo à alteridade mas também em relação ao próprio ato de Comunicação na estética (SCHAEFFER, 2000).

Originalmente, em sua formulação grega antiga, a noção de "aesthesis" está ligada à percepção imediata dos sentidos, em termos de uma "impressão" causada por algo de fora (ZEIMBEKIS, 2006). No entanto, essa perspectiva propriamente fisiológica do ato de sentir passa a ganhar outros significados derivados, ainda que todos relacionados, de algum modo, à esfera da percepçáo, mas não apenas à 
percepção de um "sentir", mas de "atribuir sentido" - e, portanto, uma eventual dimensão de passividade que possa estar presente no primeiro caso ganha um novo componente: a atribuição é um processo ativo, o que permite ler, nesse caso, o ato estético não como um momento de "recepção", mas de percepção projetiva do fenômeno que só é compreendido quando lhe é atribuído um "sentido" - e aqui a ideia de "sentir" se torna propositiva.

A noção de um "sentido comum", ou de um "senso comum", não por acaso era pensada em termos de uma "koinos aesthesis", o que sugere, de fato, que não se trata mais de uma percepção exclusivamente ligada à fisiologia tópica, mas a um processo de compreensão mais elaborado. A tradução latina, nesse ponto, talvez não surpreenda ao verter "aesthesis" para "sensus", já com a ambiguidade da palavra entre o "sentir" (como ação neurofisiológica) e o "sentido" (como "significado"). Nesse contexto, "koinos" é traduzido por "communis", na raiz do verbo "communicare", de onde derivam as noçôes de "comunicação".

Dessa maneira, talvez não seja de todo errado verificar, na origem da percepção estética, um componente ligado ao ato de comunicação, sem o qual a própria percepção deixaria, em alguma dimensão, de existir enquanto tal - a esse respeito, a observação de que o ato de sentir só pode acontecer quando há uma interação entre o sujeito que percebe e o objeto percebido seja mais do que um truísmo, mas implique a noção da constituição de uma intersecção entre ambos, uma "participação", no conceito medieval do "participatio", "fazer parte", de um elemento comum aos dois polos.

O estético e o comunicacional, ao que se pode sugerir, mantêm uma ligação necessária para sua mútua realização - no centro de ambos está a proposição de existência de uma relação entre dois ou mais termos; pensa-se, assim, antes a relação como um todo do que propriamente o "medium" dessa interação. A partir disso é possível trilhar alguns espaços para pensar o que é o fenômeno (CAUNE, 1997; COSTA, 1999).

Pensar a comunicação em perspectiva relacional é a concepção de fundo de sua perspectiva estética, resgatando a ideia de que o ato comunicacional lida, em primeira e última instância, com seres humanos em uma dimensão de partilha de uma racionalidade implícita no uso da palavra - o logos que se manifesta na racionalidade do ato comunicacional, mas que nele não se esgota; ao contrário, se torna imediatamente atraído pelo pathos e mesmo pelo eros dentro dos quais se desenvolve qualquer perspectiva interacional; a noção de uma estética da comunicação trabalha a perspectiva de que os "dispositivos interacionais", tal como denominados por Braga (2007), se referem a uma noção de relação que contempla, para além do estritamente racional, também o afetivo e o sensível em uma aesthesis necessária ao estabelecimento do vínculo comunicacional. É por conta disso que não se presume um componente estético do conceito de comunicação sem que se leve em conta as possibilidades e limites do compartilhamento da experiência da sensibilidade que inclui, no momento relacional, as condiçóes de apropriaçáo recíproca do outro.

É imperativo observar, nesse sentido, a possibilidade de traçar uma genealogia dos estudos de "comunicação" que corre paralela aos estudos de "mídia e comunicação" tal como se desenvolveram ao longo do século XX e XXI. A 
perspectiva de uma estética da comunicação, ou a busca por dimensôes estéticas na definição da "comunicação", se relaciona com uma visão do conceito que não se limita ao conjunto das interaçóes midiáticas, mas, ao contrário, procura aprofundar o elemento propriamente relacional - e, de certa maneira, mais amplo - atrelado a essa perspectiva. Dessa maneira, uma tradiçáo dos estudos de linguagem e de arte, ou de hermenêutica e estética, fornece um dos referenciais de maior importância para o deslindamento de alguns elementos estéticos do conceito de comunicação.

A comunicação, em seu componente estético, está relacionada à busca pela compreensão do âmago dos processos comunicacionais que prescindem ou não estão necessariamente ligados à perspectiva dos "meios de comunicação de massa" ou "meios de comunicação digitais". Além disso, a comunicação em sua relação com a estética destaca a especificidade dos elementos comunicacionais em processos mais amplos do que essa perspectiva - e, ao mesmo tempo, não se amplie a ponto de tornar irreconhecível o que caracteriza a comunicação. Não se deve confundir, no uso deste nome, a ideia de uma "estética da comunicação de massa”, importante disciplina de alguns cursos universitários que, no entanto, não contempla uma identificação imediata com o que se está pensando neste texto (CAMPBELL, 1976).

Uma estética da comunicação, dessa maneira, propóe a experiência radical e reflexiva de uma alteridade com a qual o desejo de vínculo total não pode se refletir senão na abertura para o ato de experienciar o outro (COUTINHO, 1976); talvez não seja por acaso que Ferrara (2013) proponha uma distinção entre a "comunicação", como substantivo fechado, - e aqui se poderia resgatar, inclusive, uma perspectiva de substância da comunicação que poderia de alguma maneira se tornar equivalente ao polo do "transmitir", tal como enfeixado por Lima $(1983,2001)$ - e o "comunicar”, como verbo, ação aberta dentro de uma indeterminação decorrente da impossibilidade ontológica de apreensão completa não apenas de um outro, mas de mim mesmo enquanto receptáculo especular da visada fenomênica dessa alteridade.

A estética da comunicação trabalha o elemento da aesthesis como uma sensibilidade ativa no sentido de construir, no indivíduo, uma compreensão dessa alteridade que o define; é na relação com essa alteridade que o próprio sentido do si-mesmo é construído e desestabilizado a cada momento, o que permite pensar que o componente estético do conceito de comunicação prevê, diretamente, a abertura do "comunicar" - no sentido mencionado por Ferrara - sobre o eventual fechamento da "comunicaçáo" como um ato terminado e completo. A complexidade desse fenômeno, aliás, molda-se na abertura recíproca ao diálogo; uma estética da comunicação, nesse ponto, torna-se eminentemente relacional, dando-se apenas no momento em que há uma possibilidade de interação; não se força uma resposta do outro, lembra Buber (2011).

A dimensão estética da comunicação coloca em cena, com especial destaque, alguns problemas de constituição dialógica de identidade e alteridade. Um de seus problemas é pensar as condições de apropriação sensível reflexiva do outro de maneira que seja possível não apenas "ver o mundo" com os olhos da alteridade, 
mas entender, em perspectiva dialógica, os modos de sentir a realidade constituídos - e constituintes - dessa alteridade; pensar e sentir a partir do outro como maneira de compreender melhor o sentir, o viver e o pensar de si mesmo está no âmago de um processo estético da comunicação que procura desenvolver o sentido da comunicação como um "compartilhar" que permita, ou demande, um envolvimento para além do cognitivo.

Isso se chocaria, a princípio, com a mencionada impossibilidade ontológica de apreensão do outro. No entanto, o ato de comunicação não parece implicar uma identificação dissolutiva na alteridade, mas a participação em algo que caracterize a formação de um espaço comum definido pelo contato, pela intersecção característica da relação comunicativa. É nesse sentido que a perspectiva de uma dimensão estética da comunicação sublinha o aspecto de sentir o outro, não apenas entendê-lo na formação de um entendimento comum, mas também na partilha de uma sensibilidade comum. Daí a possibilidade de pensar a diferença proposta por Buber (2011) entre o "diálogo", compreendido como a dimensão quase que exclusivamente linguístico-cognitiva de uma aproximação entre duas pessoas - próxima, em alguma medida, à racionalidade comunicativa do "entendimento" habermasiano - que procuram se fazer entender em uma situação, e o "dialógico", entendido como proposta vivencial de abertura para um outro com o qual se compartilha algo mais do que uma série de assertivas relacionadas ao reconhecimento de uma realidade objetiva, mas também se volta para a compreensão da subjetividade do outro, seus afetos e sua sensibilidade.

\section{Dimensões comunicacionais da experiência estética}

A experiência estética não pode ser concebida separadamente da experiência em geral como algo que privilegia a apreciação de objetos artísticos. Argumentamos aqui a favor de uma noção de estética que não se limite ao belo ou ao juízo do gosto (KANT, 1993; LYOTARD, 1993), mas que valorize a experiência que se processa através dos objetos culturais, considerando-os para além de seu suporte material.

Rodrigues (1994) indica que a experiência tem origem na vivência de fenômenos ou de acontecimentos. Ele cita três tipos-ideais de experiência: a do mundo natural, do mundo intersubjetivo e do mundo intrasubjetivo. Essas três formas de experiência estão imbricadas: elas determinam e são determinadas pelo uso da linguagem e da comunicação para a produção de sentidos e entendimentos compartilhados. Assim, chamamos de experiência não uma trajetória de vida linear e previamente determinada, mas sim um conjunto de descobertas e acontecimentos que vão se articulando de forma coerente, e que possa ser narrativizado.

A experiência de um indivíduo contém as fragilidades, as contingências e as alteraçóes pelas quais ele passa ao longo de seu contato com o mundo, consigo mesmo e com os outros. Um dos objetivos da experiência é fazer com que o indivíduo, ao passar por ela (ou ao fazer uma experiência), não seja mais o mesmo (DEWEY, 2005; QUÉRÉ; OGIEN, 2005). Dewey inclusive nos chama a atenção para o fato de que "em toda experiência há um elemento de padecimento, de sofrimento, em sentido amplo" (2005, p. 93). 
Uma experiência pesa sobre nós, pois consiste em algo mais do que colocar algo sobre a consciência, implicando uma reconstrução que pode ser penosa. Assim, uma experiência apresenta uma conexão entre padecer e agir, produzindo mudanças no sujeito e em seu ambiente, solicitando dele uma postura reflexiva, ou seja, agir sobre as condiçóes factuais de sua vida e se engajar em um processo de realizaçáo de si mesmo.

A autorrealização, para Dewey (2005), depende de um engajamento moral do sujeito que se coloca em uma posição não só de ter uma experiência, mas de fazê-la, no sentido forte do termo. Assim, fazer uma experiência implica sair de uma posição de passividade (mas não de passibilidade) para construir uma reação consciente diante daquilo que nos afeta. Sofrer uma experiência pode náo ser táo produtivo quanto fazer uma experiência, uma vez que esta exige do sujeito uma posição de agente, e não de quem padece.

Fazer uma experiência é vital para a construção do indivíduo como sujeito político, responsável por suas açôes e por sua contribuição singular. A esteticidade da experiência em Dewey está no equilíbrio entre padecer e fazer, de modo que aquilo que é imediatamente sentido possa ser organizado, ordenado e voltado para um encadeamento dos elementos que configuram a percepção e a ação. Sob esse aspecto, a experiência em Dewey assume uma característica narrativa em que os padeceres "são os elementos correspondentes ao ritmo e provêm unidade, salvam a obra da falta de objetivos representada pela pura sucessão de excitaçóes" (DEWEY, 2005, p. 105). Sofrer uma experiência nos ensina, segundo ele, a refletir sobre as consequências de um fazer anterior, auxiliando-nos a antecipar e construir roteiros de açôes iluminados por aquilo que já foi extraído e conservado, "encadeando, uns após os outros, os pequenos atos e pequenas percepçôes” (RANCIÈRE, 2000, p. 40).

Essa definição de experiência pode ser aproximada daquela construída por Gumbrecht (2006, p. 57), que indica que a experiência estética não é da ordem da epifania, mas resulta de um "processo gradual de emergência de algo que se impóe à nossa consciência”. Ele afirma que "a experiência estética na vida cotidiana é tudo, menos repentina. Antes de se impor à nossa consciência, antes de interromper seu ritmo usual, trata-se de episódios onde o ser de uma coisa, de uma maneira literal, cresce em nós" (2006, p. 59).

Sob esse ângulo, a estética permite uma experiência não da ordem da epifania, mas do estranhamento provocado por uma série de episódios que se articulam por meio do encadeamento de gestos, pequenas açóes sem expectativa, possibilidades que longe de se pretenderem reveladoras e de romperem abruptamente com a cadência e o ritmo da rotina cotidiana, investem em pequenas percepçóes encadeadas e entremeadas dos silêncios que remetem ao vazio da existência, à espera sem expectativas e à dificuldade de conferir significado e sentido à sobreposição de seres e coisas. Para Rancière, "é essa a linguagem por meio da qual a ficção estética se opõe à ficção representativa" (2000, p. 56). Dito de outro modo, experiências estéticas podem produzir narrativas e podem ser organizadas narrativamente. 
A experiência proporciona uma constante reinvenção de si e das relaçôes que travamos com os outros e, portanto, deve ser interpretada como uma "forma de compartilhar, uma possibilidade de diálogo e comunicação” (LOPES, 2002, p. 249). A experiência age, assim, como uma mediação que auxilia os sujeitos a terem acesso a um entendimento produzido sobre si mesmos, sobre os outros e sobre o mundo em que vivem. Contudo, não é a experiência em sua forma "pura" que conecta os processos comunicativos às práticas sociais, mas a experiência narrativizada, ou seja, as formas narrativas empregadas na construção relacional das identidades e do conhecimento sobre o mundo. Nesse sentido, o estudo da experiência estética, enquanto processo comunicativo que envolve o autodescobrimento e a revelação do universo do outro, confere importância e destaque às mediaçóes que estruturam nossas experiências pessoais, nossas relaçóes com os outros, com o mundo concreto e com o universo ficcional (GUIMARÃES; FRANÇA, 2006; MARQUES, 2007).

Ainda que seja imediata na percepção, a experiência tem seu acontecimento marcado por uma história, ou seja, uma série de vivências mediadas por discursos sociais que provocam transformaçôes em nossos modos de sentir, de perceber o mundo e de sermos por ele atingidos (VALVERDE, 1997; LOPES, 2006). Como afirmam Quéré e Ogien (2005), a experiência é relacional, ela marca maneiras e possibilidades de compartilhar, de dialogar e de instaurar "passagens" entre diferenças e outros modos de experimentar o mundo. Lopes (2006) e Caune (1997) afirmam que a experiência estética é da ordem da transformação, uma vez que ela modifica o sujeito, suas relaçóes com mundo, com a cultura e com os outros através de uma constante recomposição de narrativas e códigos culturais.

Segundo Seel (2014), a experiência estética é um evento que irrompe, que promove fratura, criando novas possibilidades e um campo de perigos e dissensos (no sentido de Rancière) entre o já dado e o devir. A experiência estética relaciona o devir dos sujeitos a riscos indeterminados. Essa concepção se distingue radicalmente do que entendemos por "estetização da experiência". Ao contrário de uma experiência "colonizada" pela expansão da lógica de produção mercantil que homogeneiza os espaços e modos de viver subjugando os sujeitos, a experiência estética relaciona-se à potência da vida e do ser "mergulhando-o nas formas do sensível, da vida trivial e cotidiana a que se atribui a condição de escapar a uma ordem social a priori, racionalmente prevista." (GUIMARÁES, 1999, p. 579). A experiência estética reinventa as coordenadas de enunciação da vida, proporcionando uma experimentação permanente de momentos inestimáveis que sobrevivem, que resistem a uma organização de valores que empobrece a experiência. Ela se propaga para além de todos os espetáculos comprados e vendidos à nossa volta, além do mercado e dos intensos holofotes midiáticos, para se configurar nos espaços de enunciação coletiva, nos territórios existenciais e nas brechas do cotidiano, escapando aos parâmetros consensuais e às capturas do capital.

Lopes (2006, p.118) interessa-se especificamente pela experiência estética promovida por uma "poética do cotidiano", abrigada tanto na sutileza, no silêncio e na invisibilidade das relaçóes na esfera íntima e privada quanto na construção de um olhar direcionado para "as pequenas coisas, os pequenos 
dramas", para o comum que nos aparece não como impossibilidade de representação, nem como conformismo, mas como experiência capaz de gerar empatia e reconhecimento. Segundo ele, o comum é uma construção transversal que atravessa identidades e não as elimina, podendo até atravessar culturas. O comum nos oferece, então, uma possibilidade de encontro, de fraternidade precária, de empatia, sem se transformar em algo instituído, em instituição.

No que diz respeito ao campo da comunicação, é possível dizer que a discussão em torno da experiência focaliza frequentemente "os modos como os efeitos estéticos da experiência mediada incidem sobre a experiência geral dos sujeitos, seja permitindo-lhes se manter no limite do conhecido, seja reconfigurando suas atitudes e formas de compreender o mundo" (GUIMARÁES; LEAL, 2007, p. 1). A comunicação, em sua vertente relacional, procura não só identificar as narrativas midiáticas através dos parâmetros de gênero (formato) e dos dispositivos técnicos e discursos, mas procura sobretudo estabelecer interfaces entre os efeitos estéticos e a estrutura disposta por essas narrativas e os diferentes modos de organização das narrativas pessoais e coletivas que configuram as práticas sociais e a construção de entendimentos sobre o "eu" e sobre "o outro"; sobre o "nós” e o “eles” (MARQUES, 2007)

\section{Considerações finais}

Não é possível pensar numa experiência estética que corte os laços do sujeito com o mundo da vida (local de constituição do sujeito através da intersubjetividade). Ela é exatamente o contrário, pois nos arrebata do mundo através da instauração de uma outra temporalidade, mas nos devolve ao mundo modificados.

A experiência estética, "ao promover um alargamento dos horizontes de sentido e de entendimento, interfere no cotidiano, na ética e na política, estabelecendo conexôes com formas não estéticas de comunicação" (GUIMARÁES, 2002, p. 91) e, com isso, permite a reformulação dos enunciados e das regras que modelam as relaçôes sociais. Como acresce Dewey (2005, p. 46), "todos os elementos de nosso ser que são colocados em relevo dentro de realizaçóes parciais de outras experiências são unificados dentro da experiência estética”.

Fazer uma experiência, alimentar sua potência transformadora, exige uma atitude estética, uma abertura ao mundo e à experiência do outro. Mais que afirmar posiçóes demarcadas e enrijecer diferenças, a experiência estética visa a deslocar posicionamentos. Ela não se destina a isolar a experiência individual, mas se constitui através do uso da linguagem e do diálogo intersubjetivo capaz de alterar, por meio de um projeto de longo prazo, o quadro de significados sociais que configura nossos critérios afetivos, morais e políticos. A potência dos elementos discursivos proporcionados pela experiência mediada está em não deixar que nossos sentidos e razóes se fechem ao mundo do outro.

Contudo, a experiência e sua potencialidade transformadora encontram vários limites para se concretizarem. Esses limites estáo ligados à cultura e à forma como os sujeitos se percebem e se entendem reciprocamente. 
Embora saibamos que a experiência ocorre a um indivíduo, ela possui também uma dimensão que é social, uma vez que "diante das situaçôes concretas, ela concerne tanto às regras e convicçóes que nos governam (e das quais não duvidamos), quanto à significação (aberta à problematização) que passamos a conceder aos novos fenômenos que experimentamos" (GUIMARÁES; FRANÇA, 2006, p. 100).

A experiência estética não pode deixar o sujeito, como ele era antes de fazer tal experiência, inalterado. Há um movimento de transformação quando se faz uma experiência que é capaz de "me projetar para além do perímetro que me define como sujeito" (VALVERDE, 2007). Sob esse aspecto, a experiência estética deve ser concebida como um processo que abrange quatro dimensóes principais: a) a autocompreensão dos sujeitos; b) a experiência da relação com o outro; c) os vínculos com a cultura e com os enunciados que constroem a relação social; e d) o projeto de autoconstrução e de construçáo cultural em longo prazo (CAUNE, 1997).

Nossa relaçáo com os textos midiáticos, com as imagens, com as obras de arte e com os objetos se faz dentro de diferentes contextos nos quais essa relação primeira é partilhada, em uma segunda instância, de modo intersubjetivo. Constituímo-nos enquanto sujeitos ao nos apropriarmos das coisas, da ordem sensível que nos interpela e que nos convida à autodescoberta via relação com a alteridade. Constituímo-nos enquanto sujeitos também quando resistimos aos objetos e aos textos culturais. A experiência é, portanto, o lugar onde o sujeito se constrói conflitivamente. Ela possui um caráter privado, subjetivo, que, entretanto, não fica preso ao sujeito, pois através da linguagem e da comunicação, o sujeito retira a experiência do domínio interno, para depois retornar a ele.

O lugar do outro na experiência estética é marcante: ele nos interpela e nos provoca de um modo diverso do que aquele provocado pela obra de arte. A mediação discursiva e dialógica que existe entre o "eu" e o "outro" requer uma resposta, um posicionamento, um reconhecimento, um sinal de que há reciprocidade e de que ela pode transformar os sujeitos em relação.

A experiência estética mantém estreitos laços com a experiência mediada. De um lado, a experiência estética se mostra através dos modos de narrar e representar as relaçóes concretas dos sujeitos e, de outro lado, ela ganha forma e intensidade quando os sujeitos são expostos e afetados por narrativas que os conduzem a questionar e a reformular sentidos e interpretaçôes. A experiência estética, "vinculada a uma situaçáo e baseada em um conjunto de pressuposiçóes compartilhadas, permite alargar e corrigir uma pré-compreensão dada ou, ainda, introduzir, de maneira provocadora, um ponto de vista desviante" (GUIMARÁES, 2006, p. 16).

$\mathrm{Na}$ vida cotidiana, onde estão imersos os sujeitos e suas práticas, espera-se da experiência estética a elaboração de uma força que estabelece algo que pode ser compartilhado pelos sujeitos pertencentes a uma dada comunidade afetiva e política. A experiência estética se vê investida da função de transformar o cotidiano em 
um lugar de experiências de alteridade intensas, mesmo que pequenas (mas muito significativas). $\mathrm{O}$ cotidiano seria, então, não um reservatório de práticas culturais que se acumulam, mas a "nascente" de pontos de vista que se abrem para dimensôes outras da vivência, da sociabilidade, enfim, da própria experiência

\section{Referências bibliográficas}

ALBUQUERQUE, Afonso. Os desafios epistemológicos da Comunicação mediada pelo computador. Trabalho apresentado no 11 . Encontro da Compós. Rio de Janeiro, junho 2002.

BARROS, Laan Mendes. Os meios ou as mediaçóes: qual o objeto de estudo da comunicação? Trabalho apresentado no 17o. Encontro da Compós. São Paulo, junho 2008.

BENNET, Tony. Theories of the media, theories of society. In: Gurevich, M. et alli. Culture, Society and The Media. London: Routledge, 2003.

BRAGA, José Luiz. Dispositivos interacionais. Trabalho apresentado no 21o. Encontro da Compós. Porto Alegre, junho 2011.

BRAGA, José Luiz. Nem rara, nem ausente - tentativa. Trabalho apresentado no 21o. Encontro da Compós. Rio de Janeiro, junho 2010.

CAMPBELL, Paul. Communication Aesthetics. Today's Speech. Summer 1971.

CAUNE, Jean. Esthétique de la Communication. Paris: PUF, 1997.

COSTA, Mario. L'Estetica Della Comunicazione. Roma: Castelvecchi, 1999.

COUTINHO, Evaldo. O lugar de todos os lugares. São Paulo: Perspectiva, 1976.

DEWEY, John. L'acte d'expression. In: L'art comme expérience. Publications de l'Université de Pau, Éditions Farrago, 2005.

FELINTO, Eric. Da Teoria da Comunicação às teorias da mídia. Texto apresentado no XX Encontro da Compós. Porto Alegre: UFRGS, junho 2011.

FERRARA, Lucrécia D’Alessio. A epistemologia de uma comunicação indecisa. Trabalho apresentado no 22o. Encontro da Compós. Salvador, junho 2013.

FERREIRA, Jairo. Proposiçóes que circulam sobre a epistemologia da comunicação. Alguns sabores diferenciados possíveis em um espaço reflexivo. Trabalho apresentado no 21o. Encontro da Compós. Juiz de Fora, junho 2012.

FRANÇA, Vera Regina Veiga Crítica e metacrítica: contribuição e responsabilidade das teorias da comunicação. Trabalho apresentado no 22o. Encontro da Compós. Salvador, junho 2013.

FRANÇA, Vera Regina Veiga. Paradigmas da Comunicação: conhecer o quê? Trabalho apresentado no 9o. Encontro da Compós. Brasília, junho 2001. 
GUIMARÃES, César. Estetização da experiência ou banalização da experiência estética. In: DUARTE, Rodrigo; FIGUEIREDO, Virgínia. As Luzes da Arte. Belo Horizonte: Ed. Opera Prima, 1999.

GUIMARĀES, César; FRANÇA, Vera. Experimentando as narrativas no cotidiano. In: Na Mídia na Rua: narrativas do cotidiano. Belo Horizonte: Autêntica, 2006.

GUIMARÃES, César; LEAL, Bruno Souza. Experiência Mediada e Experiência Estética. Texto apresentado ao GT "Estéticas da Comunicação" do XVI Encontro Anual da Associação Nacional dos Programas de Pós-Graduação em Comunicação Social (Compós), realizado em Curitiba, 2007.

GUIMARÃES, César. O que ainda podemos esperar da experiência estética?. In: GUIMARÃES, César; LEAL, Bruno; MENDONÇA, Carlos. (orgs.). Comunicação e Experiência Estética. BH: UFMG, p. 13-26, 2006.

GUIMARÁES, César. O campo da comunicação e a experiência estética. In: WEBER, Maria Helena et alli (org.). Tensóes e objetos da comunicação. Porto Alegre: Sulina, 2002.

GUMBRECHT, Hans Ulrich. Pequenas crises: experiência estética nos mundos cotidianos. In: GUIMARÁES, César; LEAL, B.; MENDONÇA, C. (orgs.). Comunicação e Experiência Estética. Belo Horizonte: UFMG, 2006.

KANT, Immanuel. Obsevaçóes sobre o sentimento do belo e do sublime. Campinas: Papirus, 1993.

LIMA, Venício. Mídia: teoria e política. São Paulo: Perseu Abramo, 2001.

LOPES, Denilson. Da estética da comunicação a uma poética do cotidiano. In: GUIMARÃES, César; LEAL, Bruno; MENDONÇA, Carlos (orgs). Comunicação e Experiência Estética. Belo Horizonte: UFMG, p. 117-150, 2006.

LOPES, Denilson. O homem que amava rapazes e outros ensaios. Rio de Janeiro: Aeroplano, 2002.

LYOTARD, Jean- François. Liçóes sobre a analítica do sublime. Campinas: Papirus, 1993.

MAIGRET, Éric. Sociologie de la communication et des médias. Paris: Armand Colin, 2003.

MARCONDES FILHO, Ciro. A Comunicação no sentido estrito e o Metáporo. Trabalho apresentado no 21o. Encontro da Compós. Juiz de Fora, junho 2012.

MARQUES, Ângela. Ficção, Cotidiano e Narrativa: entre o visto e o vivido. In: Revista de Estudos de Comunicação, v. 8, n. 15, p. 2939, 2007.

MARTÍN-BARBERO, Jesus. Dos meios às mediaçôes: Comunicação, cultura e hegemonia. Rio de Janeiro. UFRJ, 1997. 
MARTINO, Luiz Cláudio. História e Identidade: Apontamentos Epistemológicos sobre a fundação e fundamentação do campo comunicacional. Trabalho apresentado no 13o. Encontro da Compós. São Bernardo do Campo, junho 2002.

MARTINO, Luis Mauro Sá A disciplina interdisciplinar. Texto apresentado no XVI Intercom Sudeste. São Paulo, 10 a 12 de maio de 2011b.

MARTINO, Luis Mauro Sá. A ilusão teórica no campo da comunicação. Famecos, n. 38. junho-. agosto. Porto Alegre, 2008.

MARTINO, Luis Mauro Sá. A influência de fatores políticos na formação epistemológica do campo da comunicação no Brasil. Texto apresentado no I Confibercom. São Paulo: agosto de 2011a.

PARRET, Herman. A Estética da Comunicação. Trad. Roberta Pires de Oliveira. Campinas, SP: Editora da UNICAMP, 1997.

PIMENTA, Francisco Paoliello. Jogos, redes sociais e a crise no campo da Comunicação. Trabalho apresentado no $5^{\circ}$ Simpósio Nacional da ABCiber. Florianópolis: UFSC, Novembro 2011.

QUÉRÉ, Louis.; OGIEN, Albert. Le vocabulaire de la sociologie de l'action. Paris: Ellipses, 2005.

RANCIÈRE, Jacques. Le Partage du Sensible, esthétique et politique. Paris: La Fabrique, 2000.

RODRIGUES, Adriano Duarte. Comunicação e Cultura: a experiência cultural na era da informação. Lisboa: Editorial Presença, 1994.

SCHAEFFER, Jean-Marie. Adieu à l'esthétique. Paris: Presses Universitaires de France, 2000.

SCHRAMM, Wilbur. Men, Messages, and Media. New York: Harper and Row, 1973.

THOMPSON, John. A Midia e a Modernidade: uma teoria social da midia. Petrópolis: Vozes, 1998.

VALVERDE, Monclar. A reconfiguração do campo da comunicação à luz do conceito de experiência. Texto apresentado ao II Simpósio Internacional da Comunicação e Experiência Estética, FAFICH/ UFMG, 16 a 19 de outubro, 2007.

VALVERDE, Monclar. A Dimensão Estética da Experiência. Textos de Cultura e Comunicação, n. 37/38. Salvador: Facom-UFBa, p. 47-61, dezembro de 1997.

ZEIMBEKIS, John. Quéest-ce qu’um jugement esthétique?. Paris: J. Vrin, 2006.

\section{Notas}

1. Este trabalho contou com o apoio do CNPq e da FAPEMIG. 